\title{
Guillermo O'Donnell (1936-2011)
}

A morte do politólogo Guillermo O’Donnell, no dia 29 de novembro do ano passado, em Buenos Aires, vítima de câncer no cérebro, encerrou uma das trajetórias intelectuais mais profícuas na área da ciência política. Seus livros e ensaios sobre autoritarismo, democratização e teoria da democracia tornaram-se clássicos das ciências sociais e leitura obrigatória nas instituições acadêmicas. O’Donnell também pesquisou e ensinou em diversas universidades dos Estados Unidos e da América Latina, tais como a Universidade de Notre Dame (onde foi diretor do famoso Instituto Kellog de Estudos Internacionais), Berkeley, Stanford e Michigan. No Brasil, foi pesquisador do IUPERJ e do CEBRAP, e nos últimos anos de sua vida esteve vinculado à Universidade de Buenos Aires. Sua destacada carreira acadêmica pode ainda ser medida pelo prêmio de contribuição aos estudos latino-americanos que lhe foi outorgado pela Latin American Studies Association, em 2006, e por sua eleição para presidente da Associação Internacional de Ciência Política na gestão 1989-1991.

Mas não foram somente os títulos, as honrarias e a passagem por universidades famosas que destacaram o nome de O'Donnell. Sua teoria sobre a queda dos regimes democráticos na América do Sul, bem como seus trabalhos posteriores sobre a transição para a democracia em muitos dos países desta região, abalaram o entendimento até então existente nos círculos acadêmicos sobre a ligação entre modernização, desenvolvimento, e democracia. Por outro lado, a tentativa de aplicação das teorias comparativas 
de transição para a realidade do leste europeu, após a queda do socialismo real, tampouco deixou de gerar polêmica e críticas vindas de especialistas em area studies, que insistiam na diferença entre o autoritarismo dos países comunistas e os regimes ditatoriais da América Latina ou do Sul da Europa.

Foi com o livro Modernização e autoritarismo, publicado em 1972, seguido pelo mais conhecido O Estado burocrático e autoritário, de 1982, que O’Donnell desenvolveu sua interpretação sobre o fenômeno do novo autoritarismo que derrubou governos democráticos em países como Brasil, Argentina, Uruguai e Chile a partir dos anos 60 e 70 do século passado. Para o cientista político argentino, este novo autoritarismo se diferenciava radicalmente das ditaduras tradicionais latino-americanas, tais como a do clã Somoza na Nicarágua, ou outras de cunho populista que existiram anteriormente na Argentina e Brasil. Ele veio à tona como exigência de uma nova etapa de modernização do capitalismo na América Latina. Sua base social não era mais a oligarquia latifundiária ou a massa urbana de descamisados, e seus líderes não faziam o perfil do caudilho populista típico. Ao contrário, o novo sistema autoritário substituiu a antiga classe política oligárquica por uma coalizão de militares, empresários e tecnocratas da burocracia estatal.

Essas eram teses inovadoras e provocativas. Afinal de contas, a percepção hegemônica de modernização, de inspiração anglo-saxônica, sempre associou este processo com o crescimento da riqueza econômica, independência da sociedade civil, e o fortalecimento de instituições e valores democráticos. Segundo O’Donnell, a modernização nos principais países latino-americanos significou, ao contrário, uma tentativa de combater a crise econômica por meio da contenção da luta de classes (destruição do poder sindical e supressão dos partidos de esquerda), controle da mídia e restrições às liberdades democráticas, arrocho salarial (como parte de novo processo de acumulação e desenvolvimento capitalistas), além de forte presença do Estado na economia. Nesse sentido, a denominação de "burocrático" a este novo sistema autoritário captura bem a aspiração desses regimes de usar as alavancas do Estado para a modernização, e substituir o apoio das massas pela despolitização da sociedade e a eficiência econômica.

O enfoque estruturalista de O'Donnell levantou críticas de outros estudiosos do colapso da democracia na América Latina. Por exemplo, Juan Linz e Alfred Stepan, editores da coletânea The breakdown of democratic regimes, preferiram explicar a queda da democracia pelas falhas de suas lideranças. 
Desconfiavam de explicações macroestruturais porque estas indicavam uma inevitabilidade do fracasso das democracias latino-americanas. Outra crítica apontava para o fato de que este novo autoritarismo constituiu-se como ditadura militar, o que exigiria uma atenção muito maior ao papel desempenhado pelas forças armadas no regime burocrático-autoritário do que foi dado por O'Donnell. ${ }^{1}$

Já em seu trabalho seguinte - a coletânea de 4 volumes Transitions from authoritarian rule, que coeditou com Philipe C. Schmitter e Laurence Whitehead - O'Donnell abandona a perspectiva estruturalista, centrando-se no comportamento das elites políticas. A justificativa para a mudança de enfoque estaria no fato de as ações individuais serem, na época da queda do autoritarismo, muito menos constrangidas pelas estruturas do que no contexto da derrota da democracia. E até por isso mesmo, um dos problemas que o autor frisa é a indeterminação e a incerteza que caracterizam a transição para a democracia. Nada garante que ela, uma vez iniciada, não possa novamente reverter para o autoritarismo. Para que tal não aconteça, muito depende da capacidade dos atores políticos de seguir estratégias realistas. ${ }^{2}$

Uma estratégia realista, para O'Donnell, ocorre quando a oposição moderada se alia com descontentes do sistema autoritário, em torno de um programa de transição igualmente não-radical - o que significa não questionar a estrutura produtiva e o sistema de propriedade, nem exigir medidas que possam assustar os dissidentes moderados do regime e suscitar uma contra-reação do regime autoritário. Presume-se que esta linha moderada de atuação incluiria igualmente a não-perseguição àqueles que cometeram abusos e violações de direitos humanos durante o período ditatorial.

Como não poderia deixar de ser, esta visão moderada e conciliatória da transição foi alvo de muitas críticas. Se o advento do regime burocrático e autoritário responde a uma necessária expansão do capitalismo, quando as desigualdades socioeconômicas persistem ou são até exacerbadas, deixar intacta tal estrutura não levaria a transição democrática a sucumbir sob o peso da estabilidade e contradições políticas geradas por tal sistema? Como construir uma democracia robusta sem enfrentar a questão das reformas

Ver, a este respeito, a análise de João Roberto Martins Filho no capítulo 2 da coletânea editada por Codato (2006).

Uma rica discussão sobre transições democráticas pode ser encontrada no artigo de Bermeo (1990, p. 359-377). 
estruturais que possibilitem uma redistribuição de renda, a redução das disparidades sociais e a incorporação de milhões de cidadãos ao mercado de trabalho, problemas presentes, em graus diversos, em todos os países latino-americanos que passaram por processos de redemocratização?

Aqui é necessário levar em conta que O’Donnell e outros estudiosos da América Latina delinearam bem as fronteiras entre a transição e a consolidação da democracia. Os autores da Transitions from authoritarian ruleentre eles, cientistas sociais destacados como Adam Przeworski, Fernando Henrique Cardoso, Kenneth Maxwell e José Maravall - escolheram vários países da América do Sul, além de Portugal e Espanha, como estudos de caso, apontando que em todos eles a transição teve êxito justamente pela habilidade dos atores políticos em conduzir o processo de redemocratização de forma realista e moderada.

O Brasil, aliás, serve de modelo de "transição pactada". A lenta e gradual redemocratização brasileira foi possível por meio da aliança entre a oposição moderada e os dissidentes do regime militar, que se uniram em torno da candidatura de Tancredo Neves, isolando tanto a ala linha-dura, denominada pelo ex-presidente Ernesto Geisel de "setores sinceros mais radicais" do regime militar, como os radicais de oposição, representados pelo Partido dos Trabalhadores. É outra, porém, a realidade da consolidação da democracia. O’Donnell argumentou que o processo de consolidação democrática exige o abandono ou pelo menos modificações substanciais nos acordos que regeram a transição para a democracia, o que abriria a possibilidade para as reformas estruturais que não foram atendidas naquele primeiro momento.

Não é preciso, porém, exagerar a dicotomia "fatores macroestruturais versus elites políticas” na teoria de Guillermo O’Donnell. Embora enfatizando um ou outro aspecto nos diferentes períodos de queda da democracia ou do autoritarismo, a verdade é que ambos os fatores estão presentes em suas análises da transição e da consolidação. Crises econômicas, por exemplo, podem anteceder tanto o colapso da democracia como a erosão de uma ditadura, mas elas não indicam os futuros acontecimentos políticos. São, no jargão da ciência política, "condições necessárias, mas não suficientes" para mudanças políticas. O que caracteriza um processo de redemocratização, segundo o politólogo argentino, é a incerteza.

Esta é uma declaração que não é do agrado de boa parte dos que lidam com a ciência política. Afinal de contas, como disciplina acadêmica com 
aspirações ao estatuto de ciência, é justamente o quadro de incertezas, contingências e imprevisibilidade do âmbito político que a ciência política busca eliminar através de seus modelos teóricos e pesquisas empíricas. O’Donnell, contudo, parecia sentir-se confortável com a incerteza política. Apenas buscava reduzi-la ou controlá-la através do que Adam Przeworski denominou a "institucionalização da incerteza" (Przeworski, 1986, p. 60). Uma democracia com instituições sólidas pode conviver sem problemas com a contingência política.

Foi justamente o desenvolvimento de instituições democráticas que pautou as últimas inquietações teóricas de Guillermo O’Donnell. Talvez decepcionado com a experiência democrática dos países latino-americanos, e possivelmente preocupado com novos surtos de populismo autoritário, ele desenvolveu o conceito de "democracia delegativa", para caracterizar democracias contemporâneas como as existentes na América Latina, onde mecanismos de voto e representação política existem, mas as instituições de accountability permanecem débeis, em um contexto de pouca participação popular e crescentes desigualdades econômicas.

O’Donnell não se aprofundou sobre as transições no leste europeu, após a queda do muro de Berlim. Mas suas ideias influenciaram os estudos sobre aquela região, que foi pesquisada por alguns de seus colegas e colaboradores, provocando reações por parte de alguns especialistas em leste europeu, inconformados com a "invasão" de sua área de estudos pela transitologia e a consolidologia. $\mathrm{O}$ debate girou em torno da seguinte questão: era a natureza do poder autoritário no leste europeu tão diferente dos regimes burocrático-autoritários da América do Sul de forma a invalidar qualquer esforço comparativo? Afinal de contas, a realidade do socialismo real, no que concerne sua ideologia, valores, estrutura socioeconômica e importância das forças armadas na estrutura do poder, distancia-se significativamente das ditaduras militares latino-americanas. Além disso, fatores internacionais e problemas étnicos são muito mais importantes no leste europeu do que na América do Sul. ${ }^{3}$

Comparativistas como Philippe Schmitter e Terry Lynn Karl, por outro lado, argumentaram que estudos comparativos não operam somente com semelhanças, mas também com diferenças. E que, apesar destas, é possível

Ver a esse respeito Bunce (1995, p. 111-127). 
traçar paralelos nos padrões de transição e consolidação entre as duas regiões. Apesar de maior participação popular, a transição para a democracia na maioria dos países do leste europeu, igual que na América Latina, obedeceu à lógica do jogo político das elites (Schimitter e Karl, 1994, p. 173-185).

Em uma de suas últimas declarações, quando já havia voltado a morar em Buenos Aires, O’Donnell disse que sua obra não passava de uma “obcecada reflexão sobre a Argentina” (Lorca, 2011). Embora seu país natal sempre estivesse presente em suas obras e pensamento, seus estudos sobre transição democrática e democracia, como tentei mostrar, influenciaram debates da América do Sul ao leste europeu, passando ainda pelo sul da Europa. Será interessante observar se a "primavera árabe" provocará um novo ciclo de debates sobre transição democrática, enriquecendo o legado teórico de Guillermo O’Donnell, comprovando sua atualidade.

\section{Referências bibliográficas}

BERMEO, Nancy. 1990. "Rethinking regime change". Comparative Politics, v. 22, n. 3, p. 359-377.

BUNCE, Valerie. 1995. "Should transitologists be grounded?". Slavic Review, v. 54, n. 1, p. 111-127.

CODATO, Adriano Nervo (ed.). 2006. Political transition and democratic consolidation: studies on contemporary Brazil. New York: Nova Science.

LORCA, Javier. 2011. "O homem que pensou o Estado" Página/12, Buenos Aires, 30 de novembro.

PZEWORSKI, Adam. 1986. "Some problems in the study of transitions to democracy”.In:O'DONNELL, Guillermo;SCHMITTER, Philipe C.\& WHITEHEAD, Laurence (eds.). Transitions from authoritarian rule: tentative conclusions about uncertain democracies. Baltimore: The Johns Hopkins University Press.

SCHIMITTER, Philippe C. \& KARL, Terry Lynn. 1994. “The conceptual travels of transitologists and consolidologists: how far to the East should they attempt to go?". Slavic Review, v. 53, n. 1, p. 173-185. 